\title{
The Geometry Variation of As-Grown Carbon Coils with Ni Layer Thickness and Hydrogen Plasma Pretreatment
}

\author{
Young-Chul Jeon, Semi Park, and Sung-Hoon Kim \\ Department of Engineering in Energy and Applied Chemistry, Silla University, Busan 617-736, Republic of Korea \\ Correspondence should be addressed to Sung-Hoon Kim; shkim@silla.ac.kr
}

Received 6 February 2013; Accepted 11 March 2013

Academic Editor: Amir Kajbafvala

Copyright ( 2013 Young-Chul Jeon et al. This is an open access article distributed under the Creative Commons Attribution License, which permits unrestricted use, distribution, and reproduction in any medium, provided the original work is properly cited.

\begin{abstract}
Carbon coils could be synthesized using $\mathrm{C}_{2} \mathrm{H}_{2} / \mathrm{H}_{2}$ as source gases and $\mathrm{SF}_{6}$ as an incorporated additive gas under thermal chemical vapor deposition system. Ni layer on $\mathrm{SiO}_{2}$ substrate was used as a catalyst for the formation of carbon coils. Ni powder was evaporated to form Ni layer on the substrate. The characteristics (formation densities, morphologies, and geometries) of as-grown carbon coils on the substrate were investigated as a function of the evaporation time for Ni catalyst layer formation. By hydrogen plasma pretreatment prior to carbon coils synthesis reaction, the dominant formation of the nanosized wave-like geometry of carbon coils could be achieved. The characteristics of as-grown carbon coils with or without hydrogen plasma pretreatment process were investigated. The cause for the control of the carbon coils geometries from the microsized type to the nanosized wave-like one by $\mathrm{H}_{2}$ plasma pretreatment was discussed in association with the stress of $\mathrm{Ni}$ catalyst layer on the substrate.
\end{abstract}

\section{Introduction}

Since the first report by Davis et al. carbon coils have been noticed because of their unique shape [1]. Spring-like helix-shaped geometry may induce an electrical current and consequently generate a magnetic field. So, the predicted electrical, magnetic, and mechanical properties of carbon coils are attractive to be used in electromagnetic absorbers in the $\mathrm{GHz}$ to $\mathrm{THz}$ regions, high sensitive nano/microsized detectors, resonators, mechanical springs, essential building blocks for the assembly of nanodevices, and so forth [2-4]. In addition, carbon coils are also predicted to have a potential application as an effective fillers for nanocomposites because their spring-like geometry would make them better anchored in embedding matrix and consequently favor a better load transfer to the matrix [5].

The production of coils-type geometry was accidental and lacks reproducibility. Furthermore, the electrical properties of helically coiled geometry may have metallic, semiconducting, or semimetallic characteristics depending on their geometry including diameter [6]. Therefore, the controlled geometry (diameter, pitch, length, and turning direction) of carbon coils would be the urgent problem to be preferentially addressed in order to achieve the controlled characteristics of carbon coils.

For the synthesis method of carbon coils, catalytic chemical vapor deposition (CCVD) technique has been noticed for an effective choice to produce carbon coils because it has the flexibility in controlling growth conditions to achieve the preferred geometry. Basically, carbon coils growth involves a decomposition-diffusion-precipitation mechanism that is initiated on the surface of the catalyst particles $[7,8]$. In this respect, the characteristics of the used metal catalyst would be the important factor to control the geometry of carbon coils besides CVD system parameters. Namely, the catalyst chemical composition, size, thickness, shape, and crystallographic orientation would play a critical role in determining the geometry of carbon coils. Up to the present, various kinds of catalysts have been widely investigated [923]. Among the metal catalysts currently used in the growth of carbon coils, Ni was regarded as an effective material for the growth of carbon coils [10, 12]. For Ni catalyst study, Ni (100) was known to give the highest coil yield followed by $\mathrm{Ni}$ (111) and then $\mathrm{Ni}$ (110) among Ni single crystal planes [13]. So, the driving force for the formation of carbon coils would be the anisotropic deposition rate of a carbon according to $\mathrm{Ni}$ single 
TABLE 1: Ni layer thickness for the samples according to the evaporation time of $\mathrm{Ni}$ powders and without or with $\mathrm{H}_{2}$ plasma pretreatment.

\begin{tabular}{lccc}
\hline Samples & $\begin{array}{c}\text { Evaporation time } \\
\text { of Ni powders }\end{array}$ & $\begin{array}{c}\text { Resulting Ni layer } \\
\text { thickness }\end{array}$ & $\begin{array}{c}5 \text { minutes } \mathrm{H}_{2} \\
\text { plasma } \\
\text { pretreatment }\end{array}$ \\
\hline A & $10 \mathrm{sec}$ & $\sim 50 \mathrm{~nm}$ & None \\
B & $20 \mathrm{sec}$ & $\sim 80 \mathrm{~nm}$ & None \\
C & $40 \mathrm{sec}$ & $\sim 150 \mathrm{~nm}$ & None \\
D & 1 minute & $\sim 250 \mathrm{~nm}$ & None \\
E & 3 minutes & $\sim 350 \mathrm{~nm}$ & None \\
F & 1 minute & $\sim 250 \mathrm{~nm}$ & Yes \\
\hline
\end{tabular}

crystal planes. The catalyst particle size was also known to be the critical factor to determine the carbon coils geometry. Tang et al. [14] observed that helical carbon structure grew from $\mathrm{Fe}_{2} \mathrm{O}_{3}$ catalyst particles with diameters $<150 \mathrm{~nm}$. At the larger size of the catalyst particle, the straight carbon structure appeared. Zhang et al. [15] reported that the coiled carbon fibers were only obtained when the size of $\mathrm{Cu}$ catalyst particles was between 30 and $60 \mathrm{~nm}$ in diameter. Hokushin et al. [16] showed that carbon nanocoils (CNCs) were only observed for $\mathrm{Fe} / \mathrm{In} / \mathrm{Sn}$ catalyst particle sizes ranging between 50 and $150 \mathrm{~nm}$. Despite these abundant efforts, the study for the geometry control of carbon coils according to the thickness of Ni catalyst layer is few up to the present.

In this work, we investigated the geometries of the asgrown carbon coils with Ni layer thickness. In addition, we introduce the method to control the geometry of carbon coils through altering the characteristics of nickel catalyst layer by $\mathrm{H}_{2}$ plasma pretreatment prior to carbon coils synthesis reaction. With or without $\mathrm{H}_{2}$ plasma pretreatment process, the syntheses of carbon coils using thermal chemical vapor deposition were performed and the geometries of as-grown carbon coils were compared and discussed.

\section{Experimental Details}

For silicon oxide substrate, about $300 \mathrm{~nm} \mathrm{SiO}$ layer on $\mathrm{Si}$ substrate was employed. They were prepared by the thermal oxidation of $2.0 \times 2.0 \mathrm{~cm}^{2}$ p-type Si (100) substrates. For Ni catalyst layer deposition on the substrates, about $0.01 \mathrm{~g} \mathrm{Ni}$ powder $(99.7 \%)$ was evaporated to form $\mathrm{Ni}$ catalyst layer on the substrate using thermal evaporator. The Ni layer thickness was manipulated by controlling the evaporation time of $\mathrm{Ni}$ powders. It was measured by the cross-sectional image of field emission scanning electron microscopy (FESEM) for the as-grown film. The evaporation time of Ni powders and the resulting Ni layer thickness for each sample were shown in Table 1.

For $\mathrm{H}_{2}$ plasma pretreatment, Ni-coated substrate was placed in radiofrequency $(13.56 \mathrm{MHz}, 25 \mathrm{~W})$ plasma enhanced chemical vapor deposition (PECVD) system prior to carbon coils deposition. $\mathrm{H}_{2}$ gas was introduced into PECVD chamber. The flow rate for $\mathrm{H}_{2}$ was fixed at 17 standard $\mathrm{cm}^{3}$ per minute $(\mathrm{sccm})$. The substrate was pretreated for 5 minutes using $\mathrm{H}_{2}$ plasma at 0.5 Torr total pressure.

For carbon coils deposition, thermal chemical vapor deposition (TCVD) system was employed. $\mathrm{C}_{2} \mathrm{H}_{2}$ and $\mathrm{H}_{2}$ were used as source gases. $\mathrm{SF}_{6}$, as an incorporated additive gas, was injected into the reactor during the initial reaction stage. The flow rate for $\mathrm{C}_{2} \mathrm{H}_{2}, \mathrm{H}_{2}$, and $\mathrm{SF}_{6}$ was fixed at 15,35 , and $35 \mathrm{sccm}$, respectively. The reaction conditions were shown in Table 2. Detailed morphologies of carbon coils-deposited substrates were investigated using FESEM. The qualities of carbon coils according to the samples were investigated in the range of $800 \sim 2000 \mathrm{~cm}^{-1}$ by a micro-Raman spectrometer (Renishaw 2000) with about $50 \mu \mathrm{m}$ spot size of Ar-ion laser.

\section{Results and Discussion}

Five samples (samples $\mathrm{A} \sim \mathrm{E}$ ) having the different Ni catalyst layer thickness were prepared. At samples A and B, namely less than $100 \mathrm{~nm} \mathrm{Ni}$ catalyst layer thickness case, the formation of as-grown carbon coils could be observed here and there on the surface of the sample.

At $\sim 150 \mathrm{~nm}$ Ni layer thickness, sample C, both the microsized carbon coils and the nanosized carbon coils were well developed on the most part of the sample surface as shown in Figures 1(a) and 1(c). Most of the nanosized carbon coils were gathered along the side of the microsized carbon coils as shown in Figures 1(b) and 1(d). The deposition aspect for the nanosized carbon coils and the microsized carbon coils seems to be almost similar irrespective of the position on the surface of sample C. Indeed, in case of more than $\sim 150 \mathrm{~nm}$ Ni layer thickness, the deposition aspect for the nanosized carbon coils and the microsized carbon coils hardly depends on the position on the surface of the sample.

At $\sim 250 \mathrm{~nm}$ Ni layer thickness, sample D, the microsized carbon coils were mostly observed on the surface of the sample as shown in Figure 2. The length of the microsized carbon coils is more than hundred micrometers as shown in Figure 2(a). The diameters of the microsized carbon coils are in the range from several micrometers to ten micrometers as shown in Figure 2(b). Compared with those of sample C, a relatively few amount of the nanosized carbon coils seems to exist along the side of the microsized carbon coils as shown in Figure 2(c). In general, many types of carbon coils-related geometries could be observed on the sample surfaces [24]. Particularly, the nanosized carbon coils could be classified into two geometrical categories, namely, wave-like nanosized carbon coil (w-NC) and knot-type nanosized coil (k-NC) (see Figure 2). In this case, most of the nanosized carbon coils have w-NC type geometry. Representative FESEM images for the microsized carbon coils are shown in Figure 3. The magnified FESEM image clearly indicates the well-developed double helix geometry for these microsized carbon coils. $\mathrm{Ni}$ catalyst grain seems to be incorporated as the form of $\mathrm{Ni}_{3} \mathrm{C}$ in the bright spot in Figure 3(b) [25].

At $\sim 350 \mathrm{~nm}$ Ni layer thickness, sample E, the density of the nanosized carbon coils is higher than that of sample D (compare Figures 4(a) with 2(a)). The high-magnified images (Figures 4(b) and 4(c)) clearly reveal that the formation of 
TABLE 2: Experimental conditions for the deposition of carbon coils.

\begin{tabular}{|c|c|c|c|c|c|c|c|c|c|}
\hline Samples & $\begin{array}{l}\mathrm{C}_{2} \mathrm{H}_{2} \text { flow } \\
\text { rate }(\mathrm{sccm})\end{array}$ & $\begin{array}{c}\mathrm{H}_{2} \text { flow } \\
\text { rate }(\mathrm{sccm})\end{array}$ & $\begin{array}{l}\mathrm{SF}_{6} \text { flow } \\
\text { rate }(\mathrm{sccm})\end{array}$ & $\begin{array}{l}\text { Total pressure } \\
\text { (Torr) }\end{array}$ & $\begin{array}{l}\text { Total deposition } \\
\text { time (min) }\end{array}$ & $\begin{array}{c}\mathrm{C}_{2} \mathrm{H}_{2} \\
\text { injection } \\
\text { time (min) }\end{array}$ & $\begin{array}{c}\mathrm{H}_{2} \text { injection } \\
\text { time (min) }\end{array}$ & $\begin{array}{c}\mathrm{SF}_{6} \text { injection } \\
\text { time (min) }\end{array}$ & $\begin{array}{c}\text { Substrate } \\
\text { temperature } \\
\left({ }^{\circ} \mathrm{C}\right)\end{array}$ \\
\hline $\mathrm{A} \sim \mathrm{F}$ & 15 & 35 & 35 & 100 & 90 & 90 & 90 & 5 & 750 \\
\hline
\end{tabular}

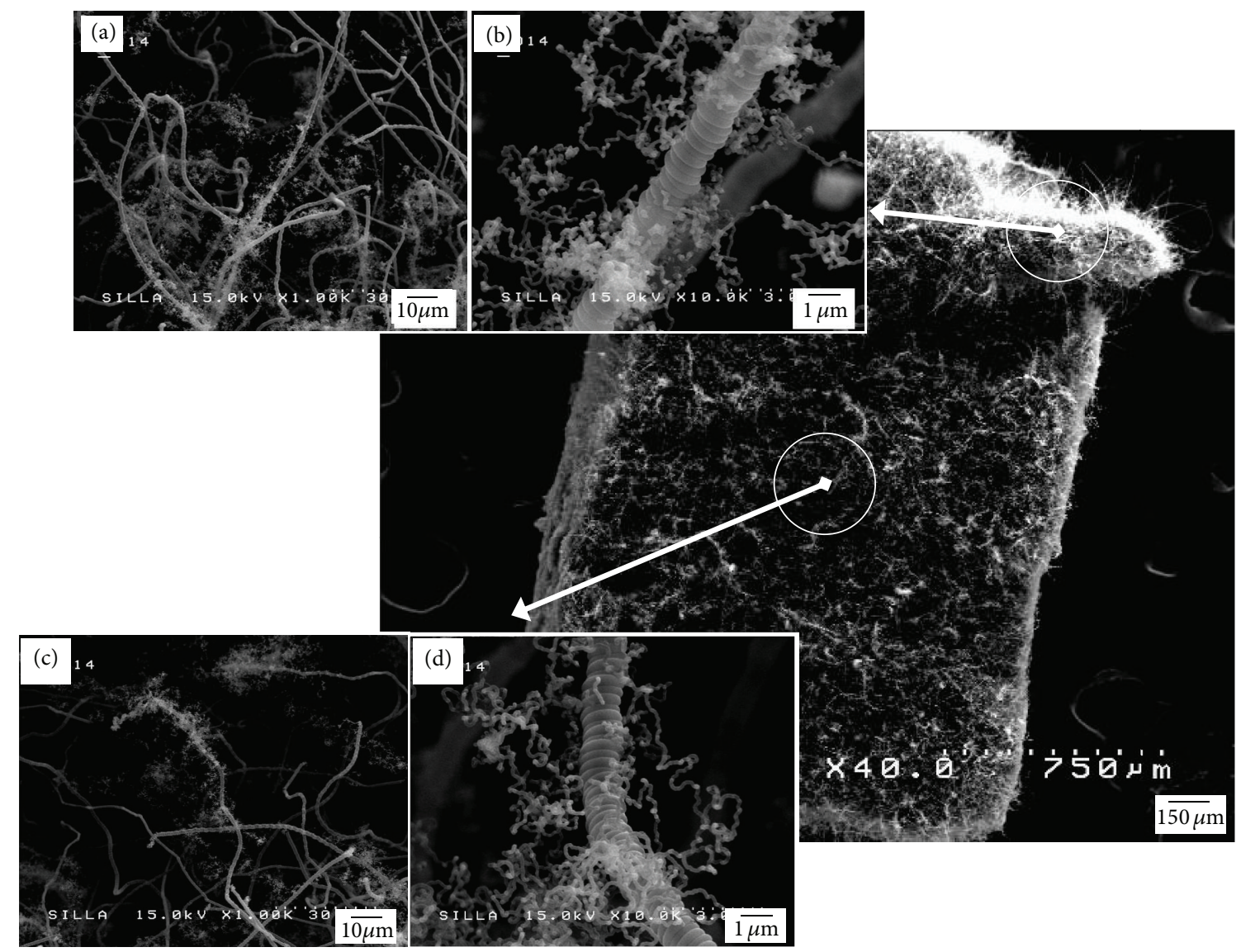

FIGURE 1: FESEM images for sample $C$ at the edge area under the magnification of (a) 1,000 and (b) 10,000 and at the center area of the substrate under the magnification of (c) 1,000 and (d) 10,000.

the microsized carbon coil was initiated by two k-NC-type nanosized carbon coils. Except for k-NCs in the microsized carbon coils, most of the nanosized carbon coils existed as a form of $\mathrm{w}-\mathrm{NC}$ geometry. Representative FESEM images for the k-NC-type nanosized carbon coils are shown in Figure $4(\mathrm{~d})$. This regularly grown nanosized carbon coil has the single helix geometry. It has a coil pitch of $\sim 300 \mathrm{~nm}$ with little coil gap and a coil diameter of $\sim 400 \mathrm{~nm}$. The carbon nanofibers that built up this coil have the circular type shape.

Using the square graph papers and FESEM images, we measured the average ratio of the occupied areas by the different-type carbon geometries, namely, the linear and the microsized geometries from several 1,000 magnified FESEM images. Under the assumption of the monolayer-grown carbon materials on the samples, the ratio of the occupied areas of carbon geometries were measured in equal-sized FESEM images. Figure 5(a) shows the variation of the ratio of the occupied areas in FESEM images for the linear and the microsized geometries as a function of the sample. The ratio of the occupied areas by $\mathrm{w}-\mathrm{NC}$ or $\mathrm{k}-\mathrm{NC}$ was also measured using several 5,000 magnified FESEM images. Figure 5(b) shows the variation of the ratio of the occupied area for $\mathrm{w}$ $\mathrm{NC}$ or k-NC as a function of the sample. For samples A and $\mathrm{B}$, this ratio could not be measured due to the unevenness according to the position on the surface of the sample. The results of Figures 5(a) and 5(b) reveal that the dominant geometry of the carbon coils would be the nanosized carbon coils with increasing $\mathrm{Ni}$ catalyst layer thickness from 250 to $350 \mathrm{~nm}$. In addition, it is believed that the geometry control for carbon coils could not be completely achieved merely by the manipulation of $\mathrm{Ni}$ catalyst layer thickness.

To fully control the geometry of carbon coils, altering the characteristics of nickel catalyst layer was performed by $\mathrm{H}_{2}$ plasma pretreatment prior to carbon coils synthesis reaction. Figure 6 shows the surface morphologies of as-grown carbon coils on the surface of the $5 \mathrm{~min}_{2}$ plasma pretreated sample 


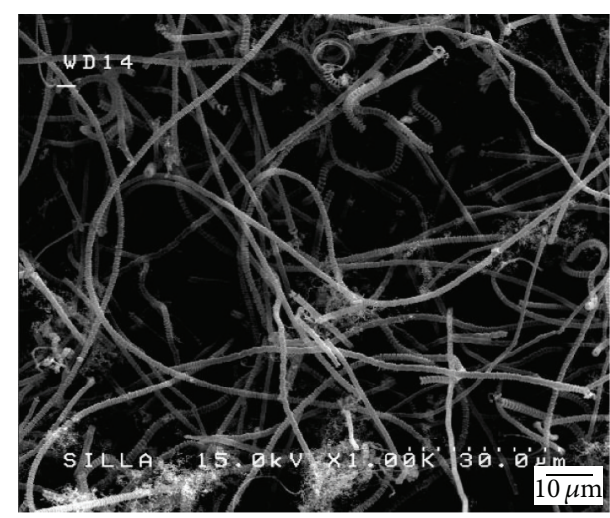

(a)



(c)

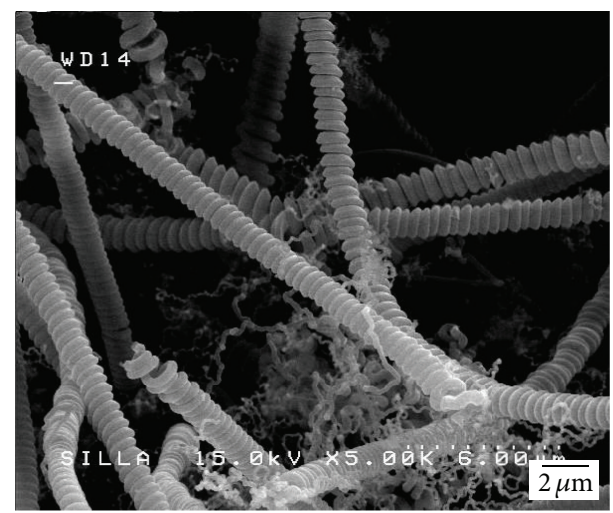

(b)

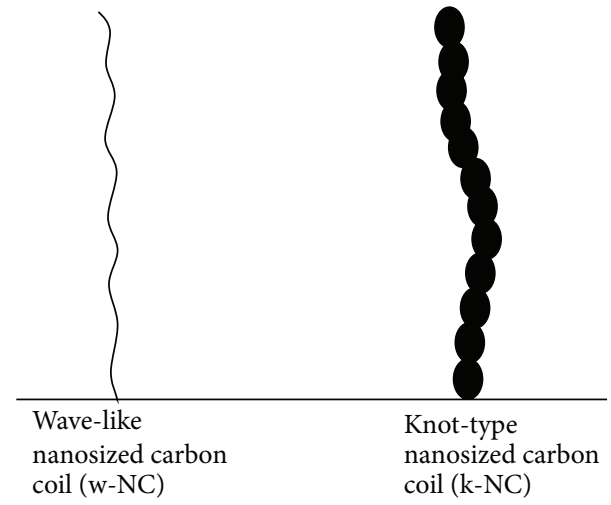

(d)

FIGURE 2: FESEM images for sample D under the magnification of (a) 1,000, (b) 5,000, and (c) 10,000, and (d) the schematic images for the typical geometries of the nanosized carbon coils.

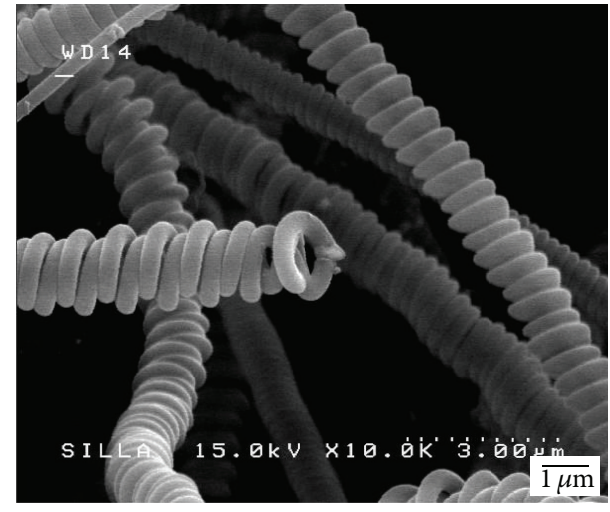

(a)

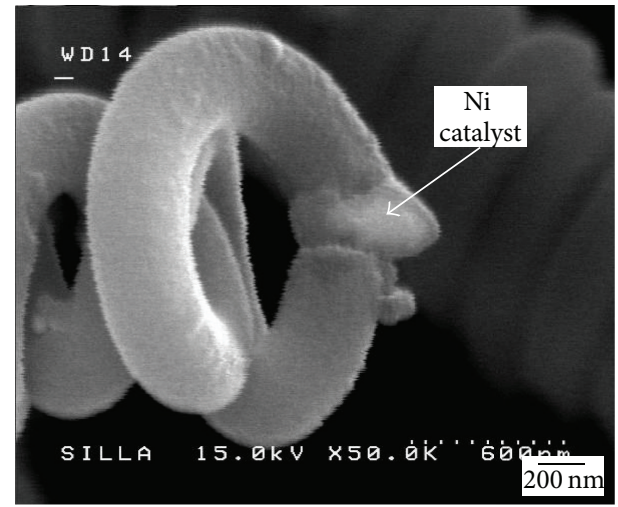

(b)

FIGURE 3: Representative FESEM images for the microsized carbon coils under the magnification of (a) 10,000 and (b) 50,000.

(sample F). The nanosized carbon coils entirely existed on the whole surface of the sample as shown in Figure 6(a). Comparing the results of sample D (see Figure 2) with this result, it is understood that the control of carbon coils geometry from the microsized type to the nanosized one is possible merely by $\mathrm{H}_{2}$ plasma pretreatment on $\mathrm{Ni}$ layer of the substrate. Most of the nanosized carbon coils have a form of w-NC-type geometry and they existed on the entire surface of the substrate. The length seems to be more than several micrometers. Their coil diameter was in the range from several nanometers to two hundred nanometers (see Figure 6(c)).

Due to the stress between the metal layer and the substrate, $\mathrm{H}_{2}$ plasma pretreated-Ni layer would be more easily peeled off and broken into very tiny nanosized $\mathrm{Ni}$ pieces and eventually scattered in surrounding area. Basically, 


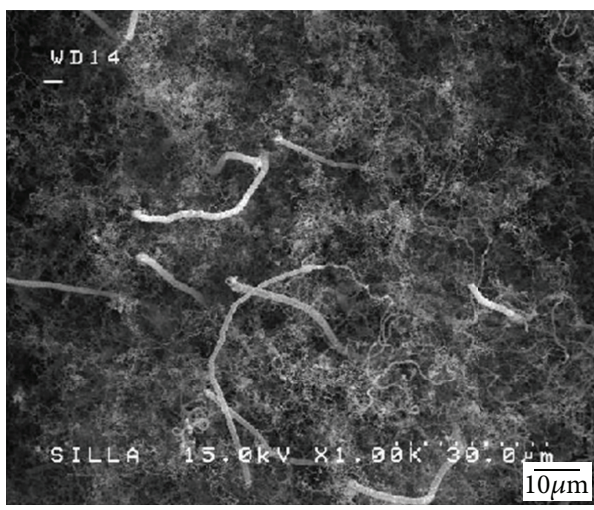

(a)

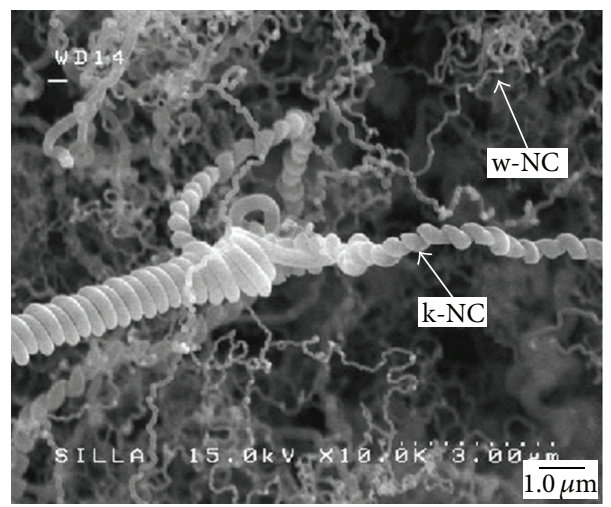

(c)

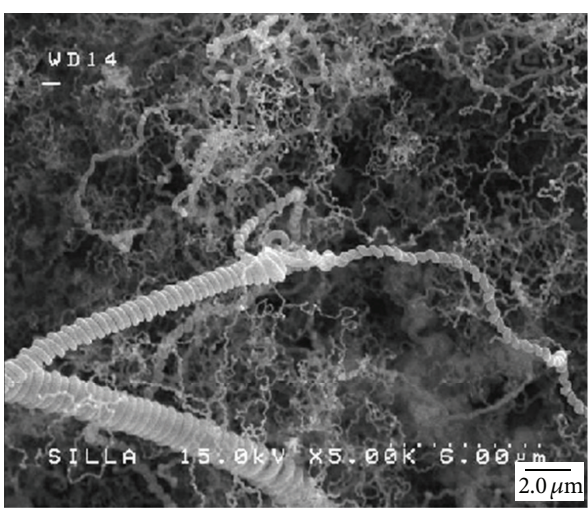

(b)



(d)

Figure 4: FESEM images for sample E under the magnification of (a) 1,000, (b) 5,000, (c) 10,000, and (d) 50,000.

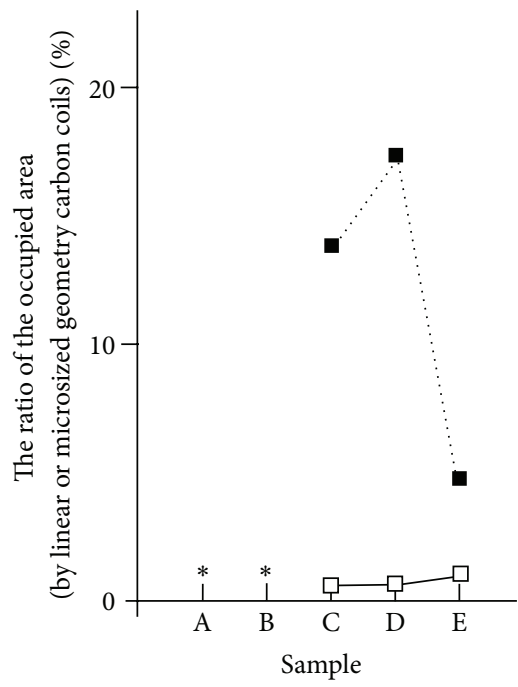

$\neg \square-$ Linear geometry

-.. Microsized geometry

(a)

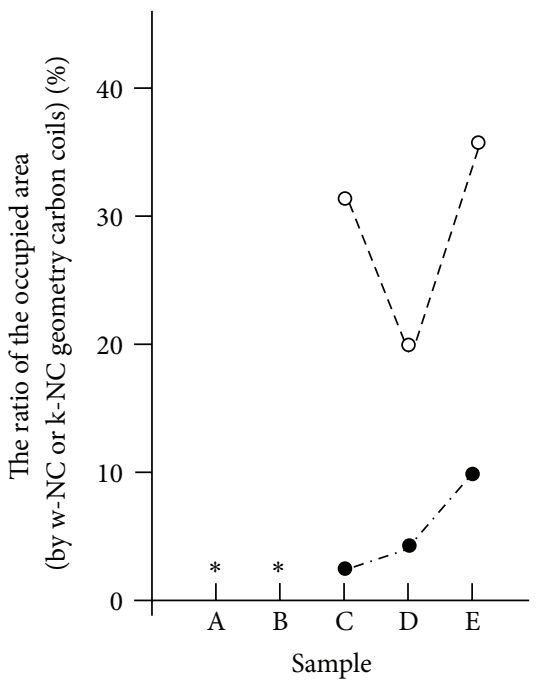

- - w-NC geometry - o- k-NC geometry

(b)

FIGURE 5: The variation of the ratio of the occupied areas in FESEM images for linear type coil, microsized coil, wave-like nanosized coil ( $w-\mathrm{NC}$ ), and knot-type nanosized coil (k-NC) as a function of the sample. The ratio of the occupied area by the linear-type and microsized coils was measured in the 1,000 magnified FESEM images and those by w-NC and k-NC in 5,000 high magnified FESEM images. 


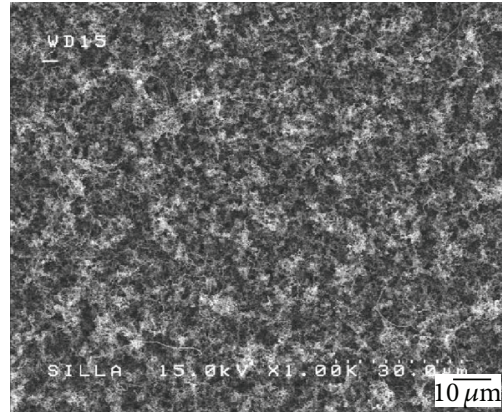

(a)



(b)

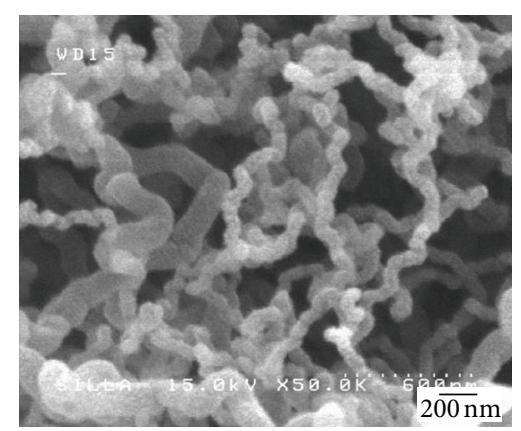

(c)

Figure 6: FESEM images for sample F under the magnification of (a) 1,000, (b) 5,000, and (c) 50,000.

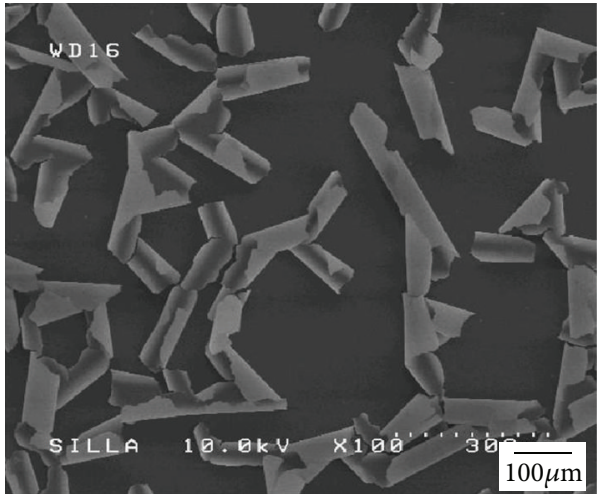

(a)

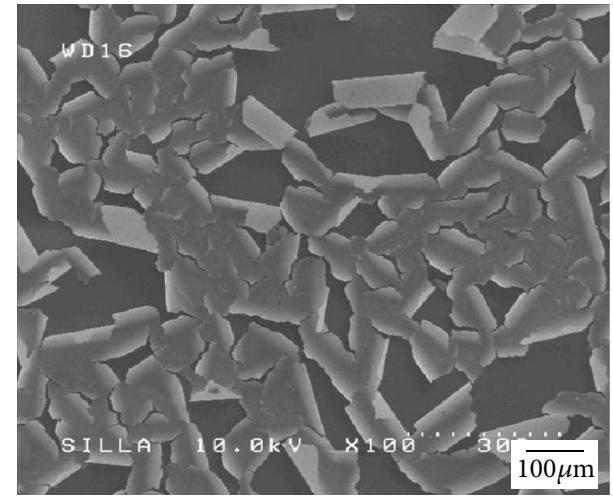

(b)

FIGURE 7: FESEM images for the peeled-Ni layers from the substrate (a) without $\mathrm{H}_{2}$ plasma pretreatment and (b) with $\mathrm{H}_{2}$ plasma pretreatment.

the mechanism of carbon coils growth depended on the metal size and shape [15]. The nanosized carbon coils were formed from the nanosized Ni pieces and they would deposit on the whole surface of the substrate. This is the reason why $\mathrm{H}_{2}$ plasma pretreatment gives rise to the dominant existence of the nanosized carbon coils on the entire surface of the substrate. Figure 7 shows FESEM images indicating the different situation of the peeled-Ni layers from the substrate without $\mathrm{H}_{2}$ plasma pretreatment (sample D, Figure 7(a)) and from the substrate with $\mathrm{H}_{2}$ plasma pretreatment (sample $\mathrm{F}$, Figure 7(b)) after cooling down the substrate from $750^{\circ} \mathrm{C}$ under vacuum. As shown in these images, the substrate with $\mathrm{H}_{2}$ plasma pretreatment gives rise to the more flaky state for $\mathrm{Ni}$ layer, which may form the nanosized geometry for carbon coils.

Meanwhile, the qualities of carbon coils for the samples without or with $\mathrm{H}_{2}$ plasma pretreatment were also investigated in the range of $800 \sim 2000 \mathrm{~cm}^{-1}$ by a micro-Raman spectrometer as shown in Figure 8. The D and G peaks in all the different samples were observed around $1350 \mathrm{~cm}^{-1}$ and $1600 \mathrm{~cm}^{-1}$, respectively. Curve fitted values of the area intensity ratios of $\mathrm{I}(\mathrm{D}) / \mathrm{I}(\mathrm{G})$ for those samples are around 2.0, which indicates the existence of the nanocrystalline aromatic

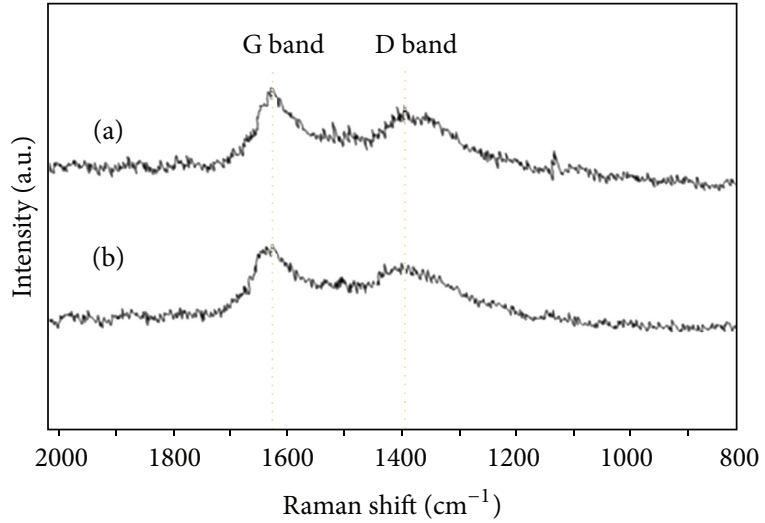

Figure 8: Micro-Raman spectra for (a) sample D and (b) sample F.

$\pi$-bonded clusters in the carbon coils [26]. I(D)/I(G) value for sample $\mathrm{F}$ is slightly higher than that for sample $\mathrm{D}$, indicating a larger presence of the disordered carbon phase in sample F. This tendency indicates the well-developed polycrystalline of the carbon coils for sample D, namely, for the microsized carbon coils on the substrate [27-30]. 


\section{Conclusions}

In case of $\mathrm{Ni}$ catalyst layer thickness less than $100 \mathrm{~nm}$, the carbon coils were formed sporadically according to the position on the surface of the sample. At more than $\sim 150 \mathrm{~nm} \mathrm{Ni}$ catalyst layer thickness, the deposition aspect for the nanosized carbon coils and the microsized carbon coils hardly depends on the position on the surface of the sample. At $\sim 250 \mathrm{~nm}$ Ni layer thickness, the microsized carbon coils were mostly observed on the surface of the sample. However, the nanosized carbon coils became dominant by increasing $\mathrm{Ni}$ catalyst layer thickness from 250 to $350 \mathrm{~nm}$.

Although the geometry of carbon coils was varied according to the different Ni layer thickness, the geometry control for carbon coils could not be completely achieved merely by the manipulation of $\mathrm{Ni}$ catalyst layer thickness. However, $\mathrm{H}_{2}$ plasma pretreatment prior to carbon coils synthesis reaction gives rise to the complete geometry change from the microsized type to the nanosized one on the entire surface of the substrate. The main cause for the geometry change of the carbon coils by $\mathrm{H}_{2}$ plasma pretreatment seems to be due to the more easily peeled-off $\mathrm{Ni}$ catalyst layer and then scattered in surroundings as tiny nanosized Ni pieces.

\section{References}

[1] W. R. Davis, R. J. Slawson, and G. R. Rigby, "An unusual form of carbon," Nature, vol. 171, no. 4356, p. 756, 1953.

[2] S. Ihara and S. Itoh, "Helically coiled and toroidal cage forms of graphitic carbon," Carbon, vol. 33, no. 7, pp. 931-939, 1995.

[3] S. Amelinckx, X. B. Zhang, D. Bernaerts, X. F. Zhang, V. Ivanov, and J. B. Nagy, "A formation mechanism for catalytically grown helix-shaped graphite nanotubes," Science, vol. 265, no. 5172, pp. 635-637, 1994.

[4] S. Hokushin, L. Pan, Y. Konishi, H. Tanaka, and Y. Nakayama, "Field emission properties and structural changes of a standalone carbon nanocoil," Japanese Journal of Applied Physics, vol. 46, no. 23, pp. L565-L567, 2007.

[5] K. Hernadi, L. Thiên-Nga, and L. Forró, "Growth and microstructure of catalytically produced coiled carbon nanotubes," Journal of Physical Chemistry B, vol. 105, no. 50, pp. 12464-12468, 2001.

[6] K. Akagi, R. Tamura, M. Tsukada, S. Itoh, and S. Ihara, "Electronic structure of helically coiled cage of graphitic carbon," Physical Review Letters, vol. 74, no. 12, pp. 2307-2310, 1995.

[7] A. K. Schaper, H. Hou, A. Greiner, and F. Phillipp, "The role of iron carbide in multiwalled carbon nanotube growth," Journal of Catalysis, vol. 222, no. 1, pp. 250-254, 2004.

[8] Z. Yu, D. Chen, B. Tøtdal, and A. Holmen, "Effect of support and reactant on the yield and structure of carbon growth by chemical vapor deposition," Journal of Physical Chemistry B, vol. 109, no. 13, pp. 6096-6102, 2005.

[9] W. Wang, K. Yang, J. Gaillard, P. R. Bandaru, and A. M. Rao, "Rational synthesis of helically coiled carbon nanowires and nanotubes through the use of tin and indium catalysts," Advanced Materials, vol. 20, no. 1, pp. 179-182, 2008.

[10] Y.-C. Jeon, J.-H. Eum, S.-H. Kim, J.-C. Park, and S. I. Ahn, "Effect of the on/off cycling modulation time ratio of $\mathrm{C}_{2} \mathrm{H}_{2} / \mathrm{SF}_{6}$ flows on the formation of geometrically controlled carbon coils," Journal of Nanomaterials, vol. 2012, Article ID 908961, 6 pages, 2012.
[11] H. Hou, Z. Jun, F. Weller, and A. Greiner, "Large-scale synthesis and characterization of helically coiled carbon nanotubes by use of $\mathrm{Fe}(\mathrm{CO})_{5}$ as floating catalyst precursor," Chemistry of Materials, vol. 15, no. 16, pp. 3170-3175, 2003.

[12] W. In-Hwang, H. Yanagida, and S. Motojima, "Vapor growth of carbon micro-coils by the Ni catalyzed pyrolysis of acetylene using rotating substrate," Materials Letters, vol. 43, no. 1, pp. 1114, 2000.

[13] S. Motojima, S. Asakura, T. Kasemura, S. Takeuchi, and H. Iwanaga, "Catalytic effects of metal carbides, oxides and $\mathrm{Ni}$ single crystal on the vapor growth of micro-coiled carbon fibers," Carbon, vol. 34, no. 3, pp. 289-296, 1996.

[14] N. Tang, J. Wen, Y. Zhang, F. Liu, K. Lin, and Y. Du, "Helical carbon nanotubes: catalytic particle size-dependent growth and magnetic properties," ACS Nano, vol. 4, no. 1, pp. 241-250, 2010.

[15] Q. Zhang, L. Yu, and Z. Cui, "Effects of the size of nanocopper catalysts and reaction temperature on the morphology of carbon fibers," Materials Research Bulletin, vol. 43, no. 3, pp. 735-742, 2008.

[16] S. Hokushin, L. Pan, and Y. Nakayama, "Diameter control of carbon nanocoils by the catalyst of organic metals," Japanese Journal of Applied Physics, vol. 46, no. 8, pp. 5383-5385, 2007.

[17] P. R. Bandaru, C. Daraio, K. Yang, and A. M. Rao, "A plausible mechanism for the evolution of helical forms in nanostructure growth," Journal of Applied Physics, vol. 101, no. 9, Article ID 094307, 4 pages, 2007.

[18] W.-C. Liu, H.-K. Lin, Y.-L. Chen, C.-Y. Lee, and H.-T. Chiu, "Growth of carbon nanocoils from $\mathrm{K}$ and $\mathrm{Ag}$ cooperative bicatalyst assisted thermal decomposition of acetylene," ACS Nano, vol. 4, no. 7, pp. 4149-4157, 2010.

[19] T.-Y. Tsou, C.-Y. Lee, and H.-T. Chiu, "K and Au bicatalyst assisted growth of Carbon nanocoils from acetylene: effect of deposition parameters on field emission properties," ACS Applied Materials \& Interfaces, vol. 4, no. 12, pp. 6505-6511, 2012.

[20] X. Qi, C. Qin, W. Zhong, C. Au, X. Ye, and Y. Du, "Large-scale synthesis of carbon nanomaterials by catalytic chemical vapor deposition: a review of the effects of synthesis parameters and magnetic properties," Materials, vol. 3, no. 8, pp. 4142-4174, 2010.

[21] A. C. Dupuis, "The catalyst in the CCVD of carbon nanotubes-a review," Progress in Materials Science, vol. 50, no. 8, pp. 929-961, 2005.

[22] S. Park, S.-H. Kim, and T.-G. Kim, "Effect of $\mathrm{Si}$ and $\mathrm{SiO}_{2}$ substrates on the geometries of as-grown carbon coils," Journal of Nanomaterials, vol. 2012, Article ID 389248, 8 pages, 2012.

[23] H. Bi, K. C. Kou, K. Ostrikov, L. K. Yan, and J. Q. Zhang, "Unconventional Ni-P alloy-catalyzed CVD of carbon coil-like micro- and nano-structures," Materials Chemistry and Physics, vol. 116, pp. 442-448, 2009.

[24] J.-H. Eum, S.-H. Kim, S. S. Yi, and K. Jang, "Large-scale synthesis of the controlled-geometry carbon coils by the manipulation of the $\mathrm{SF}_{6}$ gas flow injection time," Journal of Nanoscience and Nanotechnology, vol. 12, no. 5, pp. 4397-4402, 2012.

[25] M. Kawaguchi, K. Nozaki, S. Motojima, and H. Iwanaga, "A growth mechanism of regularly coiled carbon fibers through acetylene pyrolysis," Journal of Crystal Growth, vol. 118, no. 34, pp. 309-313, 1992.

[26] J. Robertson, "Diamond-like amorphous carbon," Materials Science and Engineering R, vol. 37, no. 4-6, pp. 129-281, 2002.

[27] K. Shibagaki, S. Motojima, Y. Umemoto, and Y. Nishitani, "Outermost surface microstructure of as-grown, heat-treated 
and partially oxidized carbon microcoils," Carbon, vol. 39, no. 9, pp. 1337-1342, 2001.

[28] F. Tuinstra and J. L. Koenig, "Raman spectrum of graphite," Journal of Chemical Physics, vol. 53, no. 3, pp. 1126-1130, 1970.

[29] S. M. Mominuzzaman, K. M. Krishna, T. Soga, T. Jimbo, and M. Umeno, "Raman spectra of ion beam sputtered amorphous carbon thin films deposited from camphoric carbon," Carbon, vol. 38, no. 1, pp. 127-131, 2000.

[30] H. Darmstadt, L. Sümmchen, J.-M. Ting, U. Roland, S. Kaliaguine, and C. Roy, "Effects of surface treatment on the bulk chemistry and structure of vapor grown carbon fibers," Carbon, vol. 35, no. 10-11, pp. 1581-1585, 1997. 

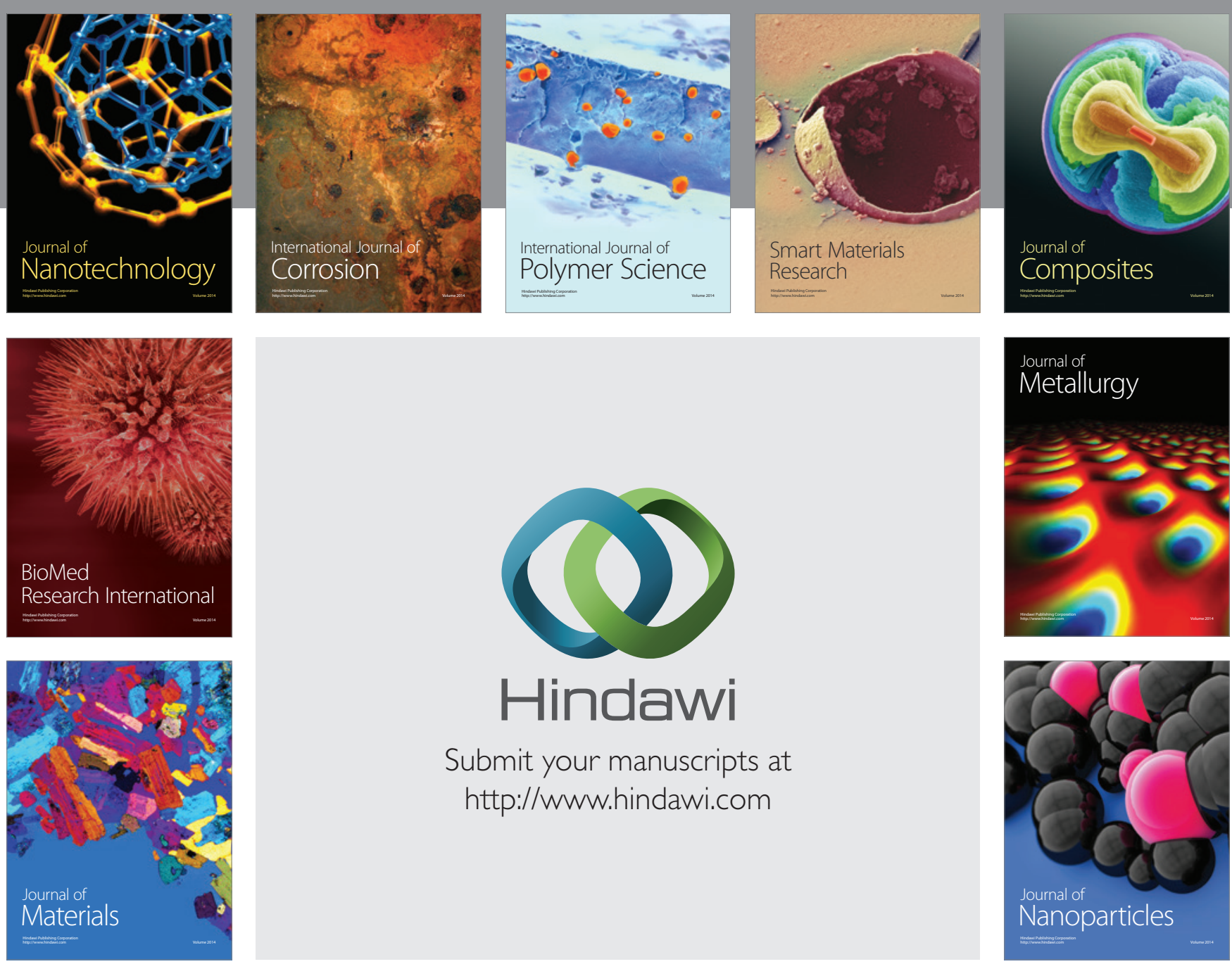

Submit your manuscripts at http://www.hindawi.com
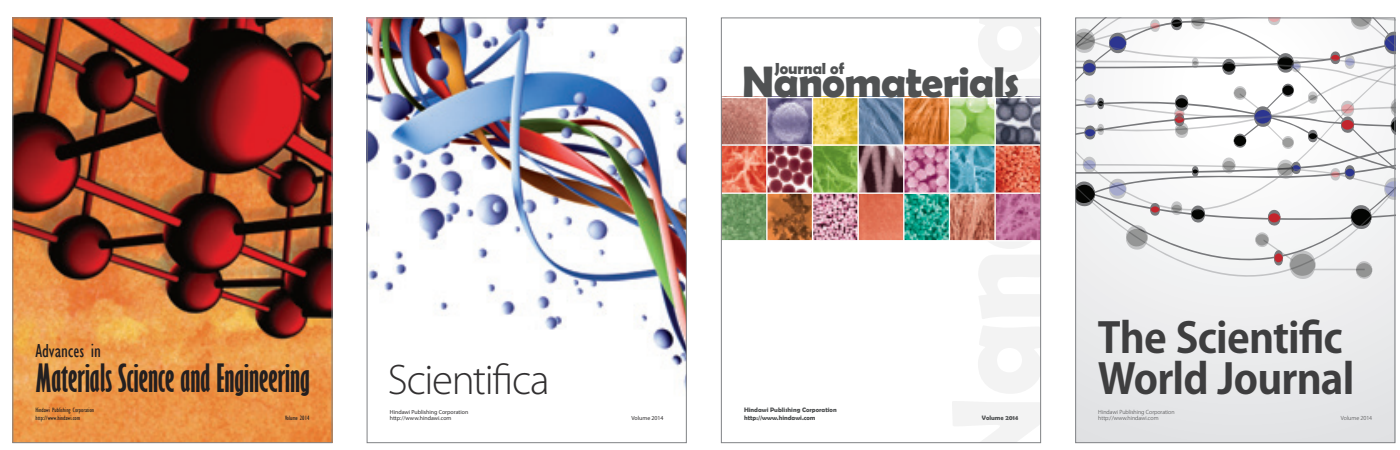

\section{The Scientific World Journal}
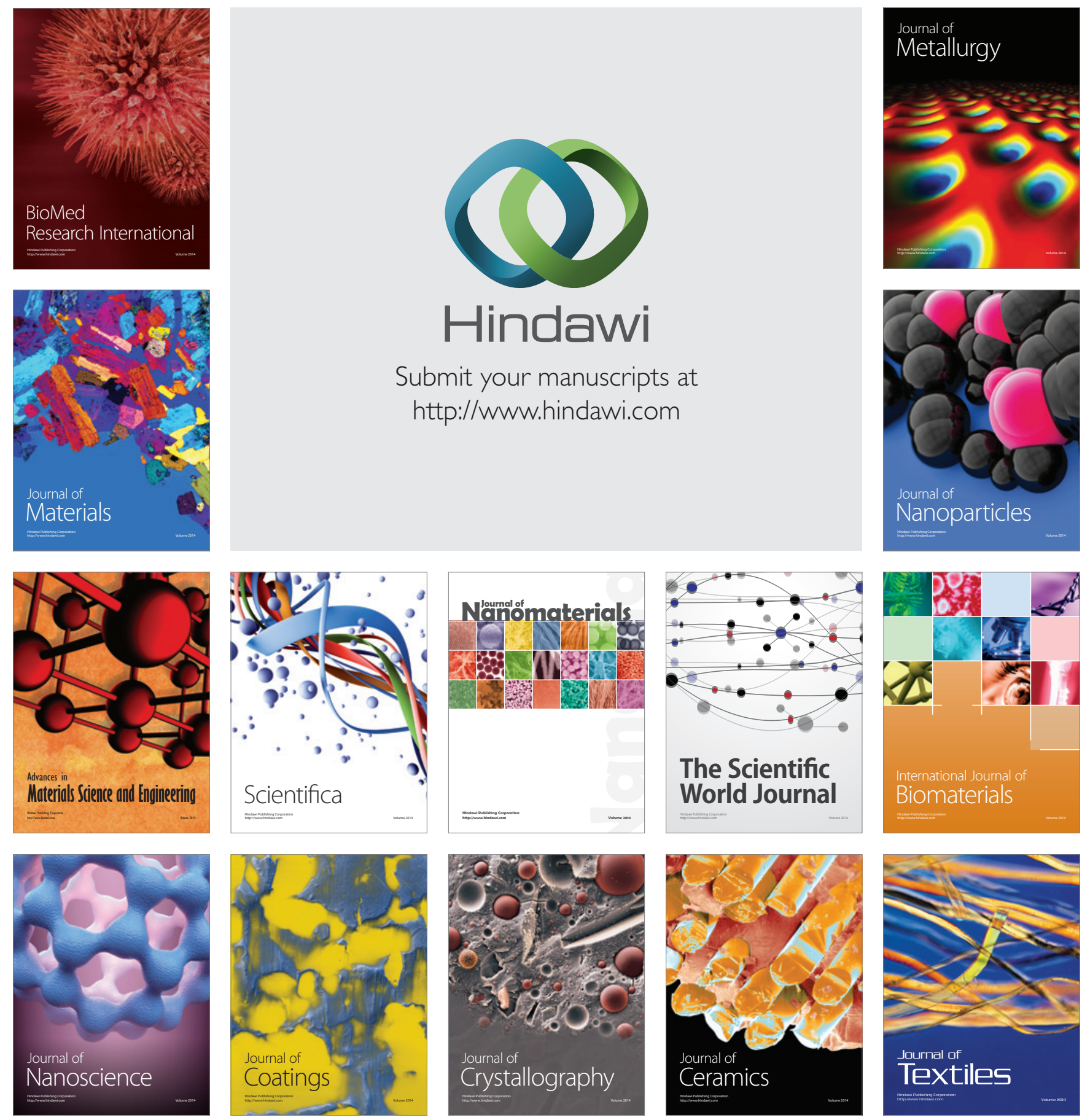